\title{
Memoir of my Brother Shoshichi Kobayashi
}

\section{by Hisashi Kobayashi}

I would like to express my sincere gratitude to Professors Shing-Tung Yau and Prof. Ming-Chang Kang for their kind invitation for me to write about my late brother Shoshichi Kobayashi. Here is a brief biography of Shoshichi.

\section{Jan. 4, 1932. Born in Kofu City}

1953. Received B.S. in Mathematics, University of Tokyo

1953-1954. Studied at Univ. of Paris and Univ. of Stras-

bourg on the French government's scholarship

1956. Received Ph.D. from University of Washington, Seattle

1956-58. Member, Institute for Advanced Study, Princeton

1958-60. Research Associate, Massachusetts Institute of Technology

1960-62. Assistant Professor, University of British Columbia

1962-63. Assistant Professor, University of California at Berkeley

1963-66. Associate Professor

1966-94. Professor

1994-2012. Professor Emeritus, and Professor of Graduate School

Aug. 29, 2012. Died of heart failure, 80 years old

Shoshichi was born on January 4th, 1932 as the first child of our parents, Kyuzo and Yoshie Kobayashi in Kofu City, Yamanashi Prefecture, Japan. Soon after his birth the family moved to Tokyo to start a business because they found such an opportunity was limited in Kofu at that time, when Japan was still in the midst of the Great Depression. The second son, Toshinori, the third son, Hisashi, which is me, and the fourth son, Hisao, were born three years apart (i.e., in 1935, 1938 and 1941, respectively). The fifth son, Kazuo, was born six years after Hisao. Unfortunately, Hisao died when he was still two, and Kazuo died soon after graduating from college.

Shoshichi was apparently of unyielding character, when he was a young boy. An episode I heard from our late mother goes like this. One day when he was four or five years old, Shoshichi had a fight with a bigger boy in the neighborhood, and was beaten in the fight. Shoshichi, angry and frustrated, went to the store owned by the boy's family, and threw a big stone to its show windows. Our parents had to make a thousand apologies for the damage.

Since Shoshichi and I were six and a half years apart, I don't recall that we played together. Shown below is a photo taken in 1941 or 42 . Shoshichi was 9 or 10 years old,

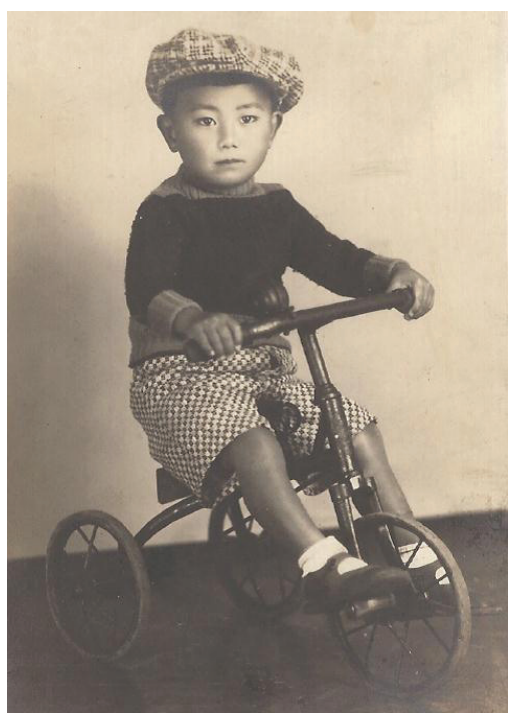

Shoshichi at age five.

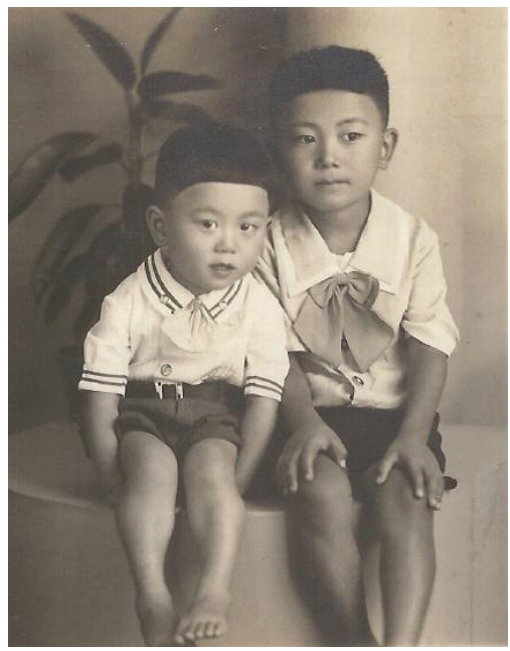

Toshinori, three years old, with Shoshichi, age six.

and I, front left, was 3 or 4 . Toshinori must have been a 1 st or 2nd grader. Our father was 37 or 38 . Mother was not in this picture, perhaps because she was pregnant of, or have just given birth to, her fourth son Hisao. Besides she was camera-shy.

Shoshichi liked mathematics since his childhood. But 
one day he faced some difficulty with a homework assignment when he was a fifth or sixth grader, in which the pupils were asked to compute the volume of the cone that can be created from a fan shape. He recalls this incident in his essay "Deeply Impressed by a Beautiful Theorem," in the May 1973 issue of Sugaku Seminar, a popular mathematics journal in Japanese.

I recall my first encounter with mathematics was when I was in the fifth or sixth grade in elementary school, where we were given a homework assignment to evaluate the volume of the cone that can be created from a given fan shape. I gave much thought to this problem at home, but could not figure out how to evaluate the height of this cone. After a while I reached the point that I needed to compute the height,

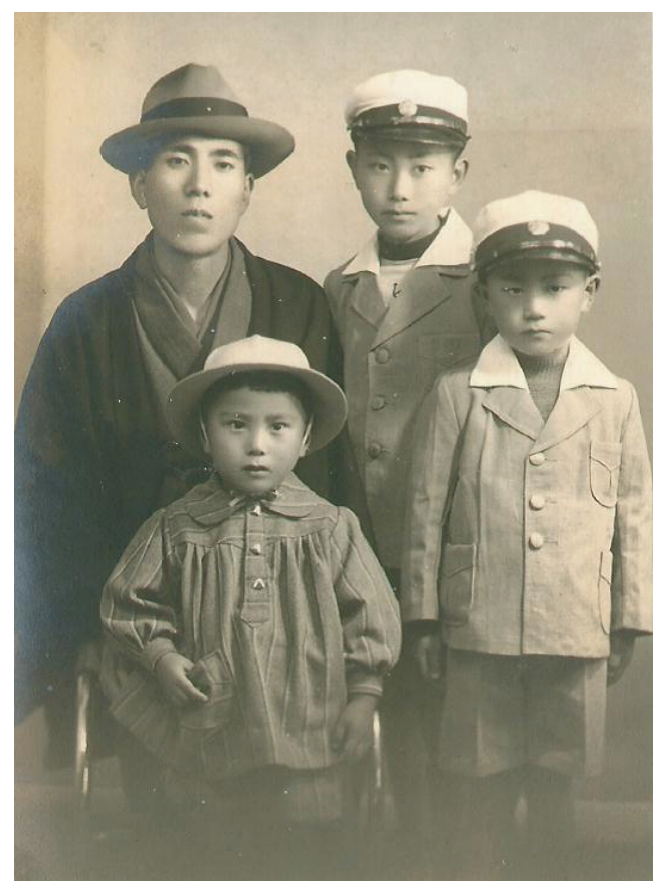

A photograph taken in 1941 or 1942: Father and Shoshichi (rear), Hisashi and Toshinori (front).

given the hypotenuse and the bottom side of a right-angled triangle, but I could not go further. Therefore, I drew the triangle on a sheet of paper and measured the height as accurately as I could.

Next day I felt relieved when the teacher told us that we did not have to work on that homework, since it was too difficult a problem. But the problem still bothered me, so I went to see the teacher during a break between classes. The teacher taught me the Pythagorean theorem (at that time in Japan the theorem was called the "Three Square Theorem" instead). Since I was not aware of either the existence or necessity of a proof for such a theorem, I was deeply impressed by this theorem when I measured the sides of various right-angled triangles and validated the theorem. The first step in mathematics is to get moved by a beautiful theorem. So perhaps this incident may have been my first step.

In April 1944, Shoshichi entered a middle (or junior high) school. He writes about that period in another essay.

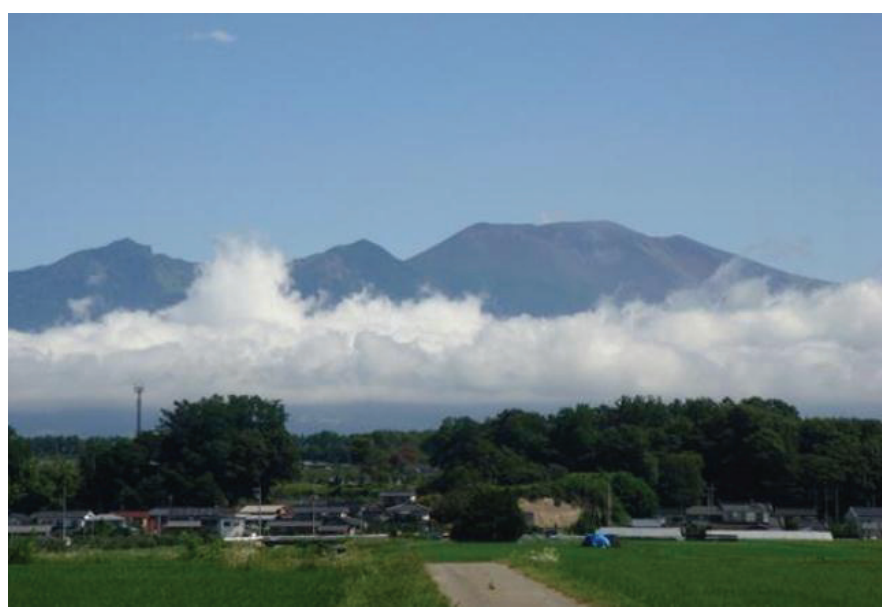

Mt. Asama viewed from Hiraga, Saku. (photograph courtesy of Nobuyoshi Yanagisawa)

In April 1944, towards the end of the war, I became a freshman of Chitose Middle School in Tokyo. This school emphasized the military training, and all freshmen were sent to Karuizawa for the training. It was still cold in April with snow remaining on the ground. We stayed in a dormitory owned by some university in Tokyo, and marched on snowy roads. So

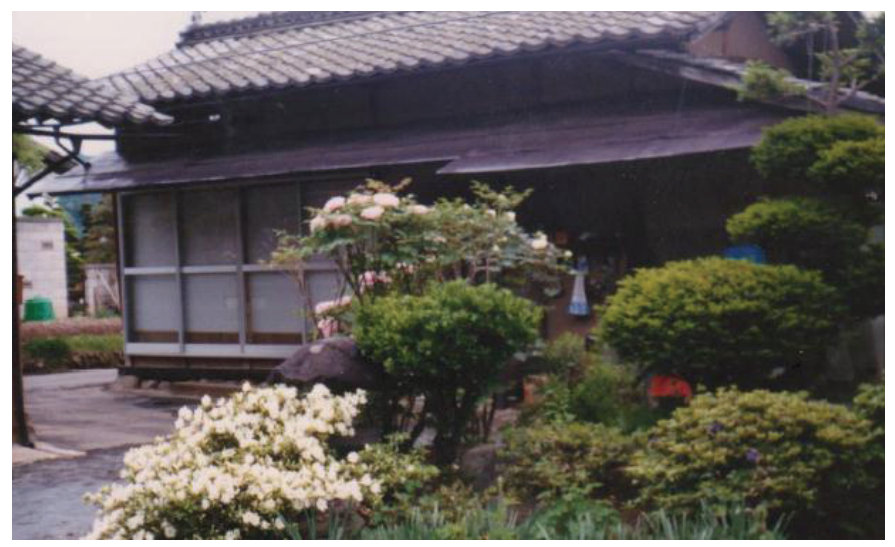

The house where the family stayed in 1947-48 (photographcourtesy of Mrs. Kiyoko Yamakawa)

the experience was quite different from the usual image associated with Karuizawa. We were divided into groups of ten students each, and the group leaders were 4th or 5th year students with good grades who intended to go to high schools and then universities. While I was discussing with our group leader at night in the dormitory, I began to think that I should 
also go to a high school after I graduate from the middle school. ${ }^{1}$

I was surprised to learn from this essay that it was not until Shoshichi entered the middle school that he developed the idea of going to a high school. Apparently, the world around him, the first son, and that around me, the third son, were quite different, although we were raised by the same parents and were only six and a half years apart.

As B-29 fighter bombers began to threaten Tokyo in 1944, we frequently had to run into an underground shelter. Shoshichi always carried mathematics books and candles with him, according to our late mother. In the spring of 1945, our whole family decided to evacuate from Tokyo, and moved to Minami-Saku, Nagano Prefecture. Shoshichi attended Nozawa Middle School near Nakagomi City, about a 40-50 minute walk from the village. I suppose that Shoshichi developed the habit of

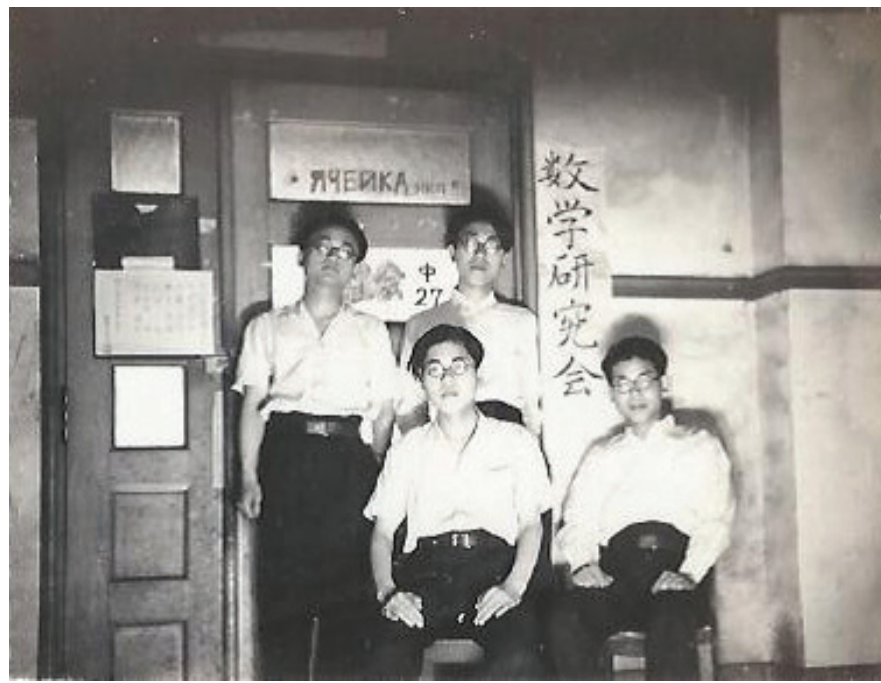

With friends of the math study group in the dormitory. Standing: Shuntaro Ito, Shoshichi. Seated: Keijiro Yamazaki, Hideki Sakurai.

thinking mathematical problems while walking to and from the school, looking at the beautiful view of Mt. Asama, an active volcano in the north from the village. Shown on the previous page are photos of Mt. Asama from the village and the house we stayed in 1947-48.

When Shoshichi became a fourth year student of Nozawa Middle School, the mathematics teacher was Mr. Muneo Hayashi, and his encounter with Mr. Hayashi turned out to be a crucial step to nurture the mathematician Shoshichi.

After the school hours, Mr. Hayashi taught me various mathematics. Matrices and matrix equations felt like magic. I was surprised to see that problems of analytic geometry became so simple...

\footnotetext{
${ }^{1}$ from "Mr. Muneo Hayashi: My Math Teacher in Middle School," in The Mathematician I Luckily Encountered, Sugaku Shobo, May 2011.
}

On my way home from the school, I sometimes accompanied Mr. Hayashi to go to the book store. It was a book store in a country side, but we found books such as "Theory of Functions" by Tanzo Takeuchi. I learned from Mr. Hayashi that there is a field of mathematics called "function theory." Although it was the period when we felt hungry all the time, every day was ex-

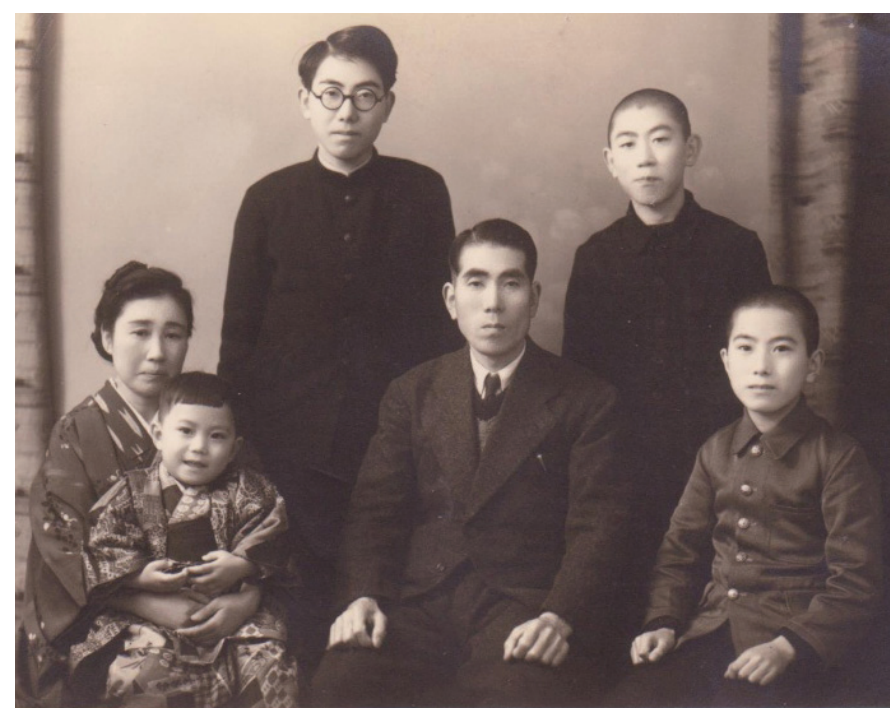

Family photograph taken in January 1950, soon after Shoshichi (rear left) had turned 18.

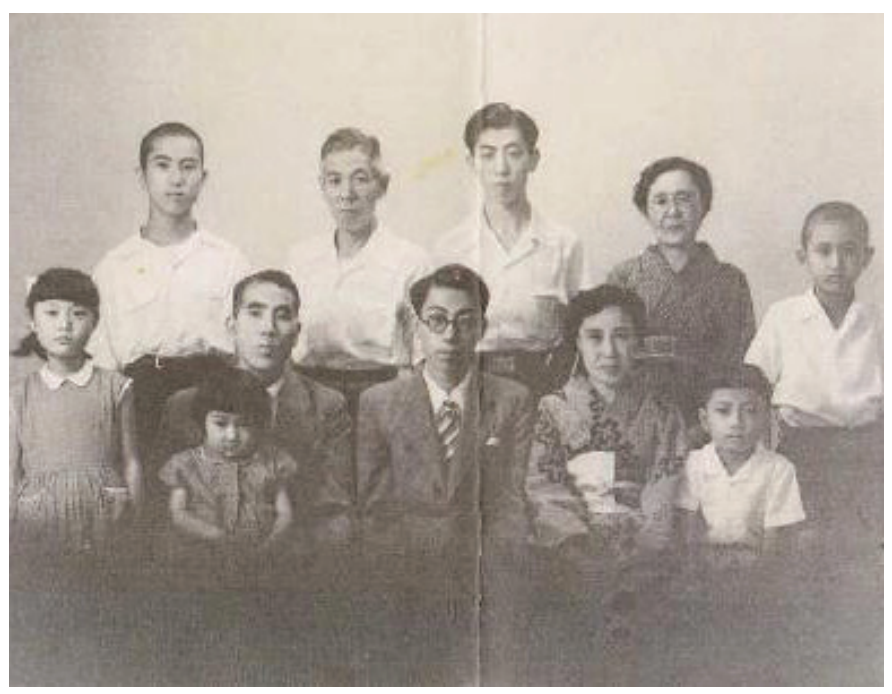

Prior to the departure to France in August, 1953. Rear row: Hisashi(15), Uncle Eizo Tanaka, Toshinori(18), Aunt Tsune

Yumoto, Minoru Tanaka (cousin)Front row: Chieko Tanaka (cousin), Father Kyuzo (49) with Kazumi Tanaka (cousin), Mother Yoshie (45), Kazuo (6).

citing to me thanks to Mr. Hayashi who taught me new subjects of mathematics, one after another. ${ }^{2}$

With regard to the process that led Shoshichi to take

\footnotetext{
2 from "Deeply Impressed by a Beautiful Theorem" in Sugaku Seminar, issue of May 1973
} 
the entrance examination of the Higher School Number One (or "Ichikoh" in Japanese abbreviation) when he was a fourth year at Nozawa Middle School, here is the story.

I was raised in Tokyo ever since a few months after birth, so I was much eager to return to Tokyo. Even in 1948, three years after the end of the war, Tokyo was not fully recovered from the war damage. There were not enough houses, electricity, etc. People who were allowed to return to Tokyo had either jobs in Tokyo or had been admitted to high schools or universities in Tokyo. Our father returned to Tokyo, preparing for restarting his business there. Like parents of a majority of people of my generation, our parents did not receive higher education, so they depended entirely on the teacher regarding their son's advancement to a

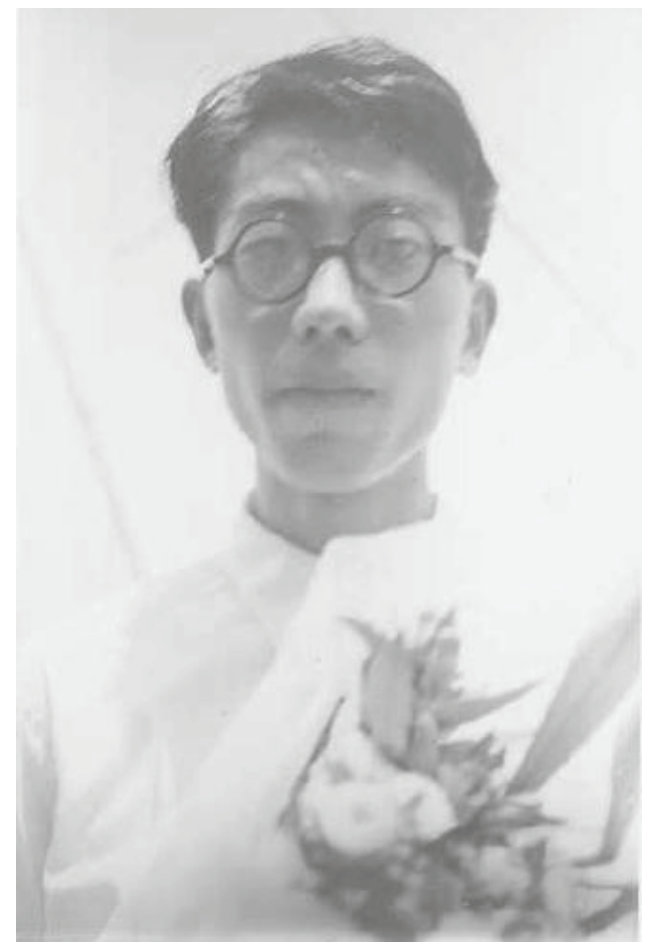

Yokohama Sea Port, August 20, 1953

high school. Luckily, my parents had no intention to let their first son take over the family business. So when Mr. Hayashi suggested that I should take the entrance examination of Ichikoh, I did not have any hesitation whatsoever, but to follow his advice. ${ }^{3}$

Mr. Hayashi's encouragement allowed Shoshichi to gain confidence to apply to Ichikoh, and our parents came to realize that their first son was gifted enough to advance to Ichikoh and then Todai. Shoshichi must have been the pride and emotional mainstay of our parents who had lost everything in the war.

\footnotetext{
${ }^{3}$ from "Mr. Muneo Hayashi, My Math Teacher in Middle School" in The Mathematician I Luckily Encountered, Sugaku Shobo, May 2011
}

In 1948, Shoshichi succeeded in entering Ichikoh in his fourth year at Middle School (skipping the fifth year) and the following year, in 1949, he entered Todai (or the University of Tokyo), under the new education system just introduced. In an essay "From Elementary School until Graduation from College (in Japanese)" in To Begin Studying Mathematics, Vol. 1, (Nippon Hyoron Sha Co. Ltd., January 2006, pp. 136-151), he fondly recalls the "Sugaku Kenkyu Kai" (or Math Study Group) founded in 1949 by Mr. Shuntaro Ito and others.

In 1951, Shoshichi advanced to the Mathematics Department and studied with the late Professor Kentaro Yano (1912-1993), who encouraged Shoshichi to strive to win the French Government's Scholarship. I was in a junior high school at that time, and I remember well that Shoshichi attended French language classes at Athenée Français and Institut français du Japon on his way home

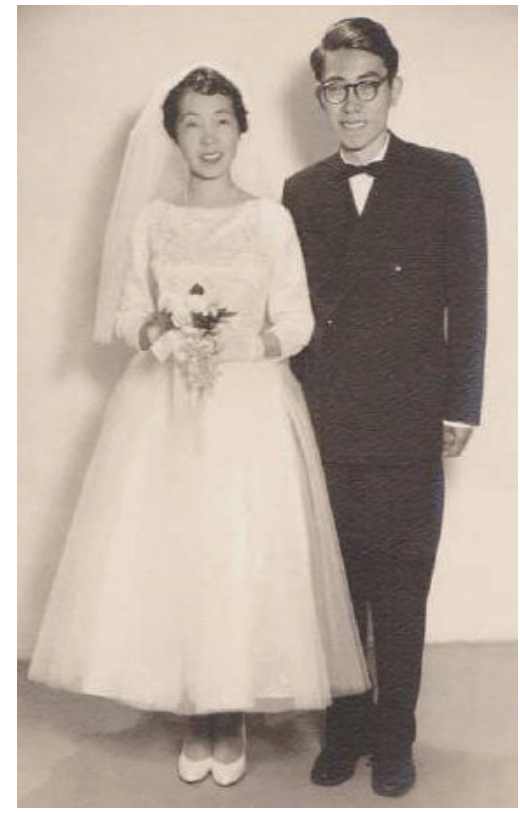

May 11, 1957, Saint Mark Cathedral, Seattle

almost every day after his classes at Todai. So he usually came home after the family finished dinner.

The examination for the French Government Scholarship was known to be very stiff (only a dozen, in all disciplines, ranging from art and literature, to the sciences, were accepted), so Shoshichi was advised to make a first trial when he was a senior at Todai. To his and Prof. Yano's surprise, however, he made it in his first attempt. The French government scholarship, however, offered only one year's stipend and tuition. A scholarship winner had to pay his or her own travel expense from Japan to France. If my memory is correct, one way travel cost about JPY 180,000, which roughly corresponded to two years' salary of a college graduate at that time. Shoshichi knew that our parents had still a big loan for the house they bought only three years before, so Shoshichi said to our father: "Father, don't worry about the money for the trip 
to France this year. I will try the competition next year again. So please come up with money next year " But our father insisted that Shoshichi should accept the scholarship and go to France that year.

He left Yokohama on August 20, 1953 for a four week trip to Marseilles by the French Ocean Liner Viet-Nam in its maiden voyage. The pianist Yuko Yamaoka (1931-2008) was one of the other twelve scholarship winners.

After a year of study in France, he moved to the University of Washington, Seattle where he received his Ph.D. in less than two years. I was wondering all these years why he did not go to Princeton or Harvard, while he suggested me to go to Princeton later. He explains his situation at that time in another essay:

In the year I graduated from Todai, I went to France from September until the summer of the following year. I studied in Paris and Strasbourg as a French Government's scholarship awardee. Then Dr. Katsumi Nomizu who had received his Ph.D. in the U.S. and was

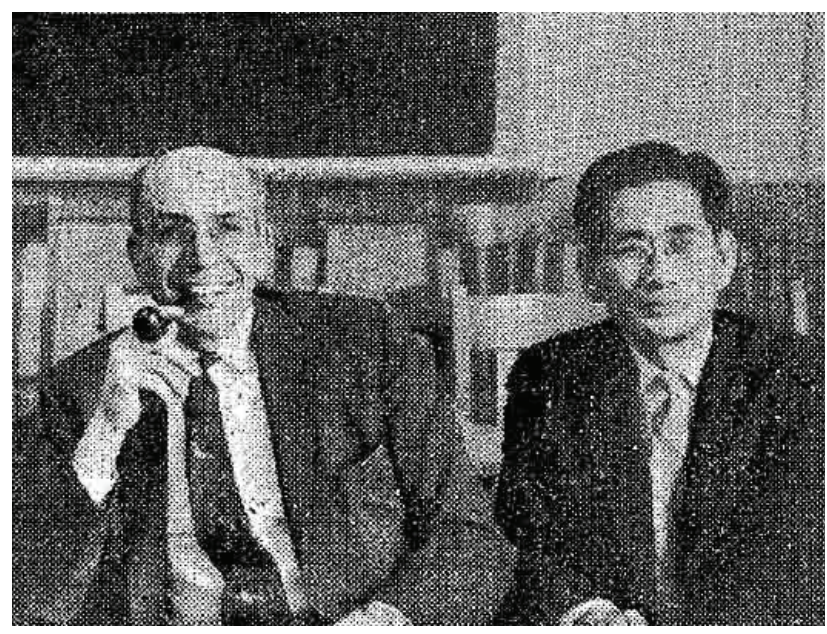

Prof. Carl B. Allendoerfer and Prof. Kentaro Yano in 1961.

visiting France for a year for research on differential geometry stirred me up, saying "Why don't you study in the U.S., instead of returning directly to Japan?" Since I needed about a year to make a doctoral thesis out of the results I obtained at Strasbourg, I became seriously interested in doing so. So I wrote to the University of Seattle in Washington where Prof. Allendoerfer who gave the first proof of the high-dimensional Gauss-Bonnet theorem was, and to the University of Chicago where Prof. Chern who found a better proof of the same theorem was, inquiring about the application and scholarships. At the same time I asked Prof. Kentaro Yano of Tokyo and Prof. Charles Ehresmann of Strasbourg for letters of recommendation. No sooner had the application form from a secretary of the Department Chair's office of the Univ. of Chicago arrived than I received a letter from Prof. Allendoerfer of Seattle (the then Department Chair) stating that he would appoint me as an assistant. So I jumped at this

\section{opportunity, without thinking of anything else! ${ }^{4}$}

The last photo shown here was taken when Shoshichi, 25 years old, married Yukiko Ashizawa. I never saw such a handsome Shoshichi, neither before nor after.

In recapitulating Shoshichi's life from his childhood until his marriage, I believe that his encounters with his seniors at Chitose Middle School in Tokyo motivated Shoshichi to think about going to a high school. Mr. Muneo Hayashi at Nozawa Middle School in Nagano discovered Shoshichi's talent in mathematics and took time to personally nurture it. Professor Kentaro Yano taught Shoshichi differential geometry, and encouraged him to study in France. Dr. Katsumi Nomizu egged Shoshichi on to study in the U.S. and Professor Allendoerfer hired him as an assistant. All of these wonderful encounters served as the sources of energy that drove Shoshichi to work as a mathematician for over fifty-five years. He led a fruitful life, blessed with a wonderful spouse and family.

Encounters with good seniors, good teachers and good friends are our irreplaceable treasure. By finding out what Shoshichi thought in his early days and how he grew up, I was convincingly reminded of the importance of our role to serve as "good seniors, good teachers" for the younger generation.

Finally, I would like to take the reader's attention to the "Shoshichi Kobayashi Memorial Website" we recently set up to compile records and news items about Shoshichi. Please visit www.ShoshichiKobayashi.com, where you will find the remembrance speeches by Profs. Arthur Ogus and Alan Weinstein of Berkeley's Mathematics Department given at the memorial service of September 8, 2012 and the beautiful poem and speech by Prof. Shing-Tung Yau and the moving speech by Shoshichi's former student, Prof. Emer. Gary Jensen (Washington Univ., St. Louis) delivered at the Memorial Reception held at the University of Tokyo on May 25, 2013. You will also find a full version of the "Shoshichi during Nozawa Middle School Days" by Prof. Emer. Noboru Naito, Shoshichi's class mate at Nozawa Middle School.

\footnotetext{
${ }^{4}$ from "My Teachers, My Friends and My Mathematics: The Period When I Studied in the United States," in Sugaku Seminar, July 1982.
} 